\title{
IRAK4 Deficiency in a Patient with Recurrent Pneumococcal Infections: Case Report and Review of the Literature
}

\section{OPEN ACCESS}

Edited by: Raffaele Badolato, University of Brescia, Italy

Reviewed by: Michael Daniel Keller, Children's National Health

System, USA Yuying Liu,

University of Texas Health Science Center at Houston, USA

${ }^{*}$ Correspondence: James Verbsky jverbsky@mcw.edu

Specialty section: This article was submitted to Pediatric Immunology, a section of the journal

Frontiers in Pediatrics

Received: 01 February 2017 Accepted: 05 April 2017 Published: 28 April 2017

Citation: Gobin K, Hintermeyer M, Boisson B, Chrabieh M, Ghandil P, Puel A, Picard C, Casanova J-L, Routes J and Verbsky J (2017) IRAK4 Deficiency in a Patient with Recurrent Pneumococcal Infections: Case Report and Review of the Literature.

Front. Pediatr. 5:83 doi: 10.3389/fped.2017.00083

\begin{abstract}
Karina Gobin ${ }^{1}$, Mary Hintermeyer ${ }^{1}$, Bertrand Boisson ${ }^{2,3,4}$, Maya Chrabieh ${ }^{2,3}$, Pegah Ghandil',3,5,6, Anne Puel 2,3, Capucine Picard ${ }^{2,3,7,8}$, Jean-Laurent Casanova, 2,3,4,7,8,9, John Routes ${ }^{1}$ and James Verbsky ${ }^{10 *}$

'Division of Asthma, Allergy and Clinical Immunology, Department of Pediatrics, Medical College of Wisconsin, Milwaukee, WI, USA, ${ }^{2}$ Laboratory of Human Genetics of Infectious Diseases, Necker Branch, INSERM U1163, Imagine Institute, Paris, France, ${ }^{3}$ Paris Descartes University, Paris, France, ${ }^{4}$ St Giles Laboratory of Human Genetics of Infectious Diseases, Rockefeller Branch, New York, NY, USA, ${ }^{5}$ Department of Medical Genetics, School of Medicine, Ahvaz Jundishapur University of Medical Sciences, Ahvaz, Iran, ${ }^{6}$ Diabetes Research Center, Ahvaz Jundishapur University of Medical Sciences, Ahvaz, Iran, ${ }^{7}$ Pediatric Hematology-Immunology Unit, Assistance Publique Hôpitaux de Paris (AP-HP), Necker Hospital for Sick Children, Paris, France, ${ }^{8}$ Center for the Study of Primary Immunodeficiencies AP-HP, Necker Hospital for Sick Children, Paris, France, ${ }^{9}$ Howard Hughes Medical Institute, New York, NY, USA, ${ }^{10}$ Division of Rheumatology, Department of Pediatrics, Medical College of Wisconsin, Milwaukee, WI, USA
\end{abstract}

Primary immunodeficiencies are genetic defects of the innate or adaptive immune system, resulting in a propensity to infections. The innate immune system is the first line of defense against pathogens and is critical to recognize microbes and start the inflammatory cascade. Sensing of microbes occurs by a number of pathogen-recognition receptors, resulting in the activation of inflammatory signal transduction pathways, such as the activation of NF-kB. Herein, we describe a case of IRAK4 deficiency, a key signal transduction molecule of toll-like and $\mathrm{L}-1$ receptors. We highlight the complexities in diagnosis of these disorders and review genetic defects of the NF-kB pathway.

Keywords: IRAK4 deficiency, MYd88 deficiency, toll-like receptors, NF-кB essential modulator, NF-кB, IкB $\alpha$

\section{INTRODUCTION}

Primary immunodeficiencies consist of various genetic defects that affect the innate and adaptive immune systems, resulting in increased susceptibility to infections. The innate immune system is the first line of defense against a wide array of pathogens and initiates the inflammatory cascade that aids in the activation of the adaptive immune response (1). Various cells (e.g., neutrophils, macrophages, and NK cells), proteins (e.g., complement, cytokines), and receptors [e.g., toll-like receptors (TLRs) and other pattern-recognition receptors (PRRs)] comprise the innate immune system. The adaptive immune system, composed of $\mathrm{T}$ and $\mathrm{B}$ lymphocytes, develops after activation of the innate immune system and is critical to clear infections. Humoral or antibody-mediated immunity predominantly functions to eradicate extracellular infections, while cellular or T cell-mediated immunity is essential for intracellular pathogens (1). We report a case of defective innate immunity to highlight one presentation of these disorders, and the diagnostic challenge they can pose.

\section{CASE REPORT}

A full-term, Caucasian, female infant was born to a healthy mother without complications. There was no family history of consanguinity, recurrent infections, or autoimmunity. She had a 5-year-old 
brother who was healthy. At 2 weeks of age, she presented to a hospital with fever to $38.3^{\circ} \mathrm{C}$ and irritability. A comprehensive evaluation for sepsis was initiated, and she was treated empirically with ampicillin and cefotaxime. Cerebrospinal fluid cultures were positive for enterovirus, and urine cultures demonstrated 10,000-100,000 colonies of Escherichia coli. A CRP at that time was normal. Voiding cystourethrogram and renal ultrasound, performed to evaluate possible secondary causes of the urinary tract infection, were normal. During admission, laboratory testing showed a white blood cell count (WBC) of $13.5 \mathrm{~K} / \mu \mathrm{L}$ with an absolute neutrophil count (ANC) of 2,565 K/ $\mu \mathrm{L}$. Follow-up testing 3 days later showed a WBC count of $7.6 \mathrm{~K} / \mu \mathrm{L}$ and $\mathrm{ANC}$ of $988 \mathrm{~K} / \mu \mathrm{L}$ (Figure 1). One week after hospitalization, the infant had fully recovered.

The patient was well until 3 months of age when she developed left inguinal swelling. She was evaluated by her pediatrician with laboratory testing showing a WBC count of $8.9 \mathrm{~K} / \mu \mathrm{L}$ and an ANC of $979 \mathrm{~K} / \mu \mathrm{L}$. The mass increased in size with erythema and induration noted, but patient had no fevers or other signs of systemic illness. Ultrasound demonstrated inflamed and possibly necrotic lymph node without evidence of abscess. The patient was admitted for administration of intravenous (IV) clindamycin, the swelling resolved, and she was discharged on oral clindamycin. Shortly after discharge, she had fevers and was diagnosed with otitis media, and her antibiotics were changed to amoxicillinclavulanate. Despite treatment, she continued to have fevers up to $40^{\circ} \mathrm{C}$, increasing erythema of the groin, and increased irritability. She was then hospitalized for IV antibiotics and incision and drainage, with cultures demonstrating Staphylococcus aureus. She responded appropriately to IV antibiotics and was sent home on oral amoxicillin-clavulanate.

The patient was seen for follow-up in her pediatrician's office 3 days after discharge. She was afebrile, not irritable, and there was no sign of infection at her surgical site. However, blood culture from the previous admission was positive for $S$. pneumoniae after 5 days of growth. She received intramuscular ceftriaxone in the office and was directly admitted to the hospital for sepsis. A complete blood count (CBC) drawn at admission showed a WBC count of $9.3 \mathrm{~K} / \mu \mathrm{L}$ with an ANC of $0 \mathrm{~K} / \mu \mathrm{L}$. To evaluate for neutropenia, neutrophil antibody testing was sent along with serial CBCs to rule out cyclic neutropenia. Abdominal and pelvic CTs were performed to exclude occult abscesses and only demonstrated reactive lymph nodes in the inguinal retroperitoneal area. With previously normal neutrophil counts with infection and absence of other cytopenias, it was thought that her current neutropenia was most likely related to consumption due to infection. The patient's blood culture drawn at admission was negative, she was well appearing, and consequently discharged home on oral amoxicillin-clavulanate.

Three weeks later, the patient was diagnosed with bilateral otitis media treated with amoxicillin (WBC $6.4 \mathrm{~K} / \mu \mathrm{L}$ with ANC of $900 \mathrm{~K} / \mu \mathrm{L}$ ). Two weeks later, she was diagnosed with right otitis media treated with cefdinir. WBC at this evaluation was $7.9 \mathrm{~K} /$ $\mu \mathrm{L}$ with an ANC of $1,422 \mathrm{~K} / \mu \mathrm{L}$. Although she was well appearing without fever, blood culture was drawn and was positive for S. pneumoniae, sensitive to cefdinir. Patient was admitted to the hospital and received IV ceftriaxone and was subsequently sent home on a course of oral cefdinir. Clindamycin prophylaxis was initiated against S. pneumoniae taking into account of the frequency and severity of the infant's infections.

The patient had serial CBCs to evaluate for possible cyclic neutropenia. It was noted that her neutrophil counts were quite variable with nadirs ranging from 500 to $700 \mathrm{~K} / \mu \mathrm{L}$, but did not vary in a cyclical pattern (Figure 1). Anti-neutrophil antibodies were negative. DNA sequencing of the ELA2 gene was normal. Serum immunoglobulins, pneumococcal antibody titers, lymphocyte subset analysis, expression of CD15 and CD18, and DHR were all normal (Table 1). Radiographs of the long bones, serum trypsinogen, and stool pancreatic elastase, sent to evaluate for Shwachman-Diamond syndrome, were normal (Table 1).

At the age of 6 months, she developed otitis media with accompanying $S$. pneumoniae bacteremia. Tympanostomy tubes were placed, and retrotympanic membrane fluid was positive for S. pneumoniae. She was treated with IV levofloxacin in the hospital, and then sent home on clindamycin prophylaxis. With the placement of tympanostomy tubes and clindamycin prophylaxis, the frequency of infections decreased, and her ANC trended upwards (Figure 1). With an improvement in her ANC and overall clinical picture, the patient was taken off of antibiotic prophylaxis.

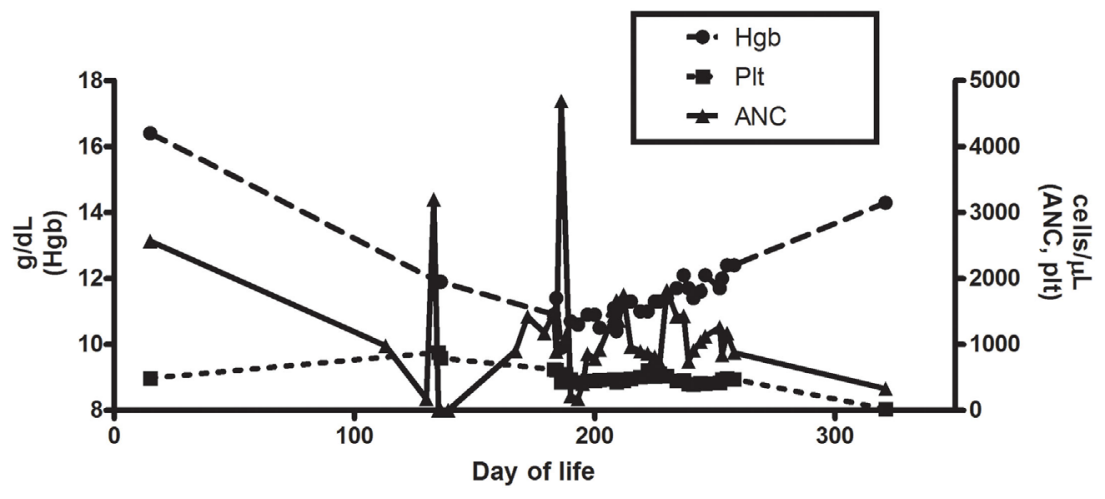

FIGURE 1 | Hemoglobin, platelet, and absolute neutrophil counts for patient during clinical course 
TABLE 1 | Immunologic and hematologic laboratory results.

\begin{tabular}{|c|c|c|}
\hline Pneumococcal vaccine titers & $\begin{array}{l}6 / 7 \text { serotypes } \\
\text { positive }\end{array}$ & \\
\hline Neutrophil antibody panel & Negative & \\
\hline $\begin{array}{l}\text { Crossreactive autoneutrophil } \\
\text { antibodies }\end{array}$ & Negative & \\
\hline ELA2 gene mutation & Negative & \\
\hline $\lg G$ & $446 \mathrm{mg} / \mathrm{dL}$ & $174-857 \mathrm{mg} / \mathrm{dL}$ \\
\hline $\lg A$ & 23 mg/dL & $10-75$ mg/dL \\
\hline $\lg M$ & $37 \mathrm{mg} / \mathrm{dL}$ & $22-95 \mathrm{mg} / \mathrm{dL}$ \\
\hline $\lg \mathrm{E}$ & $17 \mathrm{mg} / \mathrm{dL}$ & $24-85$ mg/dL \\
\hline ALC count & $4,898 / \mathrm{mm}^{3}$ & $3,900-9,000 / \mathrm{mm}^{3}$ \\
\hline Absolute B cell count & $1,567 / \mathrm{mm}^{3}$ & $430-3,000 / \mathrm{mm}^{3}$ \\
\hline Absolute T cell count & $3,233 / \mathrm{mm}^{3}$ & $2,500-5,650 / \mathrm{mm}^{3}$ \\
\hline Absolute NK cells & $147 / \mathrm{mm}^{3}$ & $170-830 / \mathrm{mm}^{3}$ \\
\hline T cell subset: CD3+CD4+ & $2,400 / \mathrm{mm}^{3}$ & $1,800-4,000 / \mathrm{mm}^{3}$ \\
\hline T cell subset: CD3+CD8+ & $686 / \mathrm{mm}^{3}$ & $590-1,600 / \mathrm{mm}^{3}$ \\
\hline T cell subset: CD4+CD45RA+ & $70 \%$ & \\
\hline T cell subset: CD4+CD45RO+ & $8 \%$ & \\
\hline B cell naïve/memory subset: CD27+ & $7 \%$ & \\
\hline $\begin{array}{l}\text { B cell naïve/memory subset: } \\
\text { lgD+CD27- }\end{array}$ & $89 \%$ & \\
\hline $\begin{array}{l}\text { B cell naïve/memory subset: } \\
\text { lgD-CD27+ }\end{array}$ & $1 \%$ & \\
\hline $\begin{array}{l}\text { B cell naïve/memory subset: } \\
\text { lgD+CD27+ }\end{array}$ & $6 \%$ & \\
\hline $\begin{array}{l}\text { B cell naïve/memory subset: } \\
\text { CD21+CD27- }\end{array}$ & $73 \%$ & \\
\hline $\begin{array}{l}\text { B cell naïve/memory subset: } \\
\text { CD21-CD27+ }\end{array}$ & $2 \%$ & \\
\hline $\begin{array}{l}\text { B cell naïve/memory subset: } \\
\text { CD21+CD27+ }\end{array}$ & $5 \%$ & \\
\hline
\end{tabular}

At 11 months of age, patient presented to an ER with emesis and fever for 1 day. She was hospitalized for presumed gastroenteritis and received IV fluids. Shortly into the hospitalization, she became listless with poor perfusion and was transferred to the pediatric intensive care unit for respiratory failure. She was intubated and started on gentamicin and vancomycin and was found to have positive blood cultures for $S$. pneumoniae. She developed cardiogenic shock, multiorgan system dysfunction, and cerebral edema with poor perfusion. She was ultimately taken off life support and expired.

Due to recent descriptions of genetic defects in the TLR pathway resulting in susceptibility to invasive infections with $S$. pneumoniae and $S$. aureus, postmortem genetic analysis was pursued demonstrating compound heterozygous mutation in the IRAK4 gene (Q293X, $831+5 \mathrm{G}>\mathrm{T}$ ). IL1 stimulation of SV40 immortalized fibroblasts failed to induce normal amounts of IL6, whereas TNF- $\alpha$ stimulation was normal confirming loss of function of IRAK4 (Figure 2). Defective responses to other TLR agonists were also demonstrated.

\section{DISCUSSION}

This case highlights the presentation of TLR defects. TLRs are a widely expressed family of PRRs that respond to conserved microbial antigens, known as pathogen-associated molecular patterns, such as lipopolysaccharides (LPS), flagellin, and singlestranded RNA (2). Upon ligand binding, TLRs induce signaling transduction pathways leading to expression of gene products

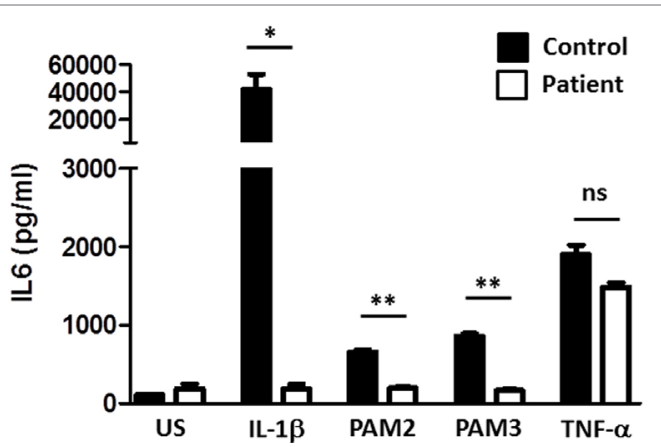

FIGURE 2 | Toll-like receptor (TLR) testing of patient fibroblasts. SV40 transformed fibroblasts of the patient, and a healthy control were stimulated as indicated and IL6 production measured. PAM2 is a synthetic TLR2 agonist. PAM3 is a synthetic TLR1/2 agonist. A t-test was used to compare each agonist response of the patient versus a control $\left({ }^{*}<0.05,{ }^{* *}<0.01\right)$.

that initiate the inflammatory cascade. TLRs are single pass transmembrane proteins with extracellular leucine-rich repeat domains and a cytoplasmic tail that shows high similarity to the IL-1 receptor family. This portion is termed as the toll/IL-1 receptor (TIR) domain. In humans, 10 TLRs have been identified. TLR1, TLR2, TLR4, TLR5, TLR6, and TLR10 are extracellular, whereas TLR3, TLR7, TLR8, and TLR9 are located intracellularly within the endosome (1).

All TLRs except TLR3 utilize MyD88 as their cytosolic adaptor and trigger the canonical pathway leading to NF- $\kappa \mathrm{B}$ activation and inflammatory cytokine gene transcription. MyD88 activates the IRAK complex, containing the protein kinase IRAK4, leading to activation of the I $\mathrm{B}$ kinase (IKK) complex (Figure 3). The IKK complex includes NF- $\kappa \mathrm{B}$ essential modulator (NEMO) and active IKKs (IKK $\alpha$ and IKK $\beta$ ). $\mathrm{NF}-\kappa \mathrm{B}$ at baseline is bound to inhibitory proteins such as $\mathrm{I} \kappa \mathrm{B} \alpha$ and $\mathrm{I} \kappa \mathrm{B} \beta$, sequestering it in the cytoplasm at baseline. Activated IKK complex leads to phosphorylation and degradation of $I \kappa B \alpha$ and $I \kappa B \beta$, leading to translocation of NF- $\kappa B$ to the nucleus (3). Translocation leads to gene transcription and expression of various cytokines such as IL1 $\beta$, IL-6, IL-12, IL-18, and TNF- $\alpha$. TLR3 utilizes an alternative pathway via TIR-domain-containing adaptor-inducing interferon- $\beta$ (TRIF) leading to the activation of TNF receptor-associated factor 3 (TRAF3) and expression of interferon regulatory factor 3 and 7. This leads to the transcription of type I interferons. TLR4 can trigger both the canonical and alternative pathways (4) (Figure 3).

\section{IRAK4/MyD88 Deficiency}

Mutations in several genes involved in the TLR signaling pathways have demonstrated to cause primary immunodeficiencies in humans. IRAK4 and MyD88 are essential for signal transduction in the TLR canonical pathway. Consequently, IRAK4 and MyD88 deficiencies are indistinguishable clinically. IRAK4 and MyD88 deficiencies, which are inherited in an autosomal recessive manner, present with invasive severe pyogenic infections with S. pneumoniae, S. aureus, and Pseudomonas aeruginosa 


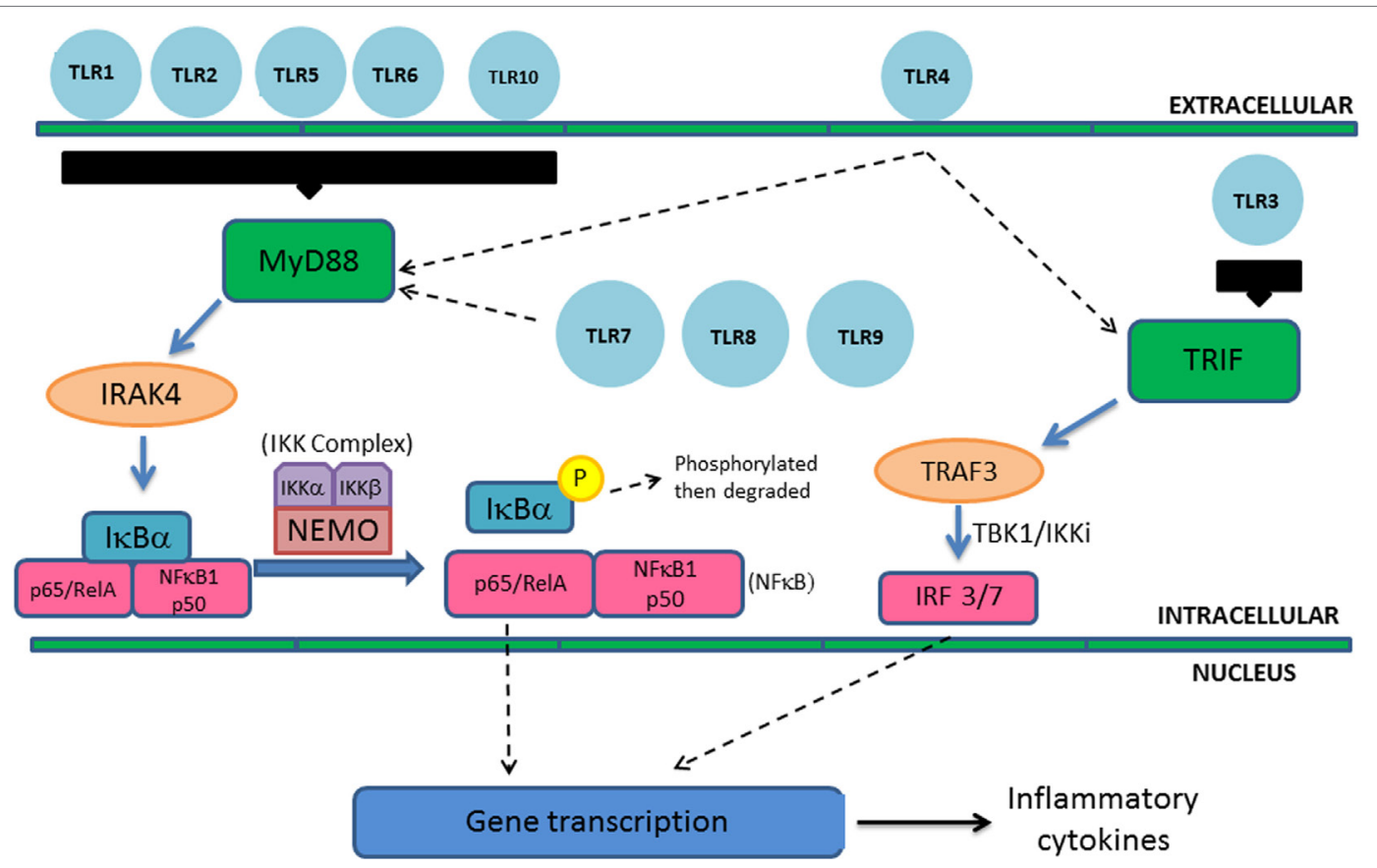

FIGURE 3 | Toll-like receptor signaling pathways. Extracellular TLRs include TLR1, TLR2, TLR4, TLR5, TLR6, and TLR10 and TLR3, TLR7, TLR8, and TLR9 are located intracellularly within the endosome. Aside from TLR3, all other TLRs operate through MyD88 leading to activation of NF-kB and subsequent inflammatory cytokine gene transcription and expression. This is an example of canonical pathway utilization; however, other subunits can be activated. TLR3 operates through the TIR-domain-containing adaptor-inducing interferon- $\beta$ pathway, while TLR4 can activate both pathways. MyD88 activates the IRAK complex (containing protein kinase IRAK4) leading to subsequent activation of the IKB kinase (IKK) complex. Activation of the IKK complex leads to phosphorylation and degradation of IKB $\alpha$ and translocation of NF-KB to the nucleus and production of inflammatory cytokines. TLR3 activation of TNF receptor-associated factor 3 results in transcription of type I interferons.

(5-8). Patients can present with meningitis, osteomyelitis, arthritis, abscesses, sepsis, and cellulitis. Affected individuals are not particularly susceptible to viral, parasitic, or fungal infections. Patients may mount a weak inflammatory response with delayed fever or minimal change in inflammatory markers (e.g., $C$ reactive protein) with infections. Antibody levels, vaccines titers, and lymphocyte subpopulations are typically normal, although glycan-specific antibody response, including hemagglutinins and pneumococcal glycans, can be defective $(9,10)$. TLR testing with agonists such as LPS or IL- $1 \beta$ will show defective responses. As children age, the rate of infections usually decrease, which is likely due to the acquisition of humoral immunity and immunologic memory. There have been no deaths reported after 8 years of age in patients with IRAK4 deficiency (6), although there is a report of a 31-year-old with recurrent infections due to IRAK4 deficiency, suggesting that infectious episodes could continue throughout life (11). Despite being susceptible to a somewhat limited spectrum of bacteria, the mortality rate in these patients is $43 \%$. Prophylactic antibiotic treatment, vaccinations against pyogenic bacteria, and immunoglobulin replacement starting early in life is recommended as prophylactic treatment (12).

\section{NEMO/IKK Complex Defects}

Central to TLR signaling is the activation of NF- $\kappa \mathrm{B}$ and defects in NF- $\kappa \mathrm{B}$ signaling leads to immunodeficiencies. There are two pathways involved in NF- $\kappa \mathrm{B}$ signaling: the canonical pathway that utilizes NEMO and the non-canonical pathway that uses $\mathrm{NF}-\kappa \mathrm{B}$-inducing kinase. Activation of the canonical pathway results in the activation of the NEMO-dependent kinases, IKK $\alpha$ and IKK $\beta$, which phosphorylate serine residues on I $\mathrm{KB} \alpha$ and $\mathrm{I} \kappa \mathrm{B} \beta$ resulting in their ubiquitination and degradation. Degradation of these inhibitors allows for NF- $\kappa \mathrm{B}$ translocation into the nucleus and subsequent gene transcription $(9,13)$. Complete deficiency of NEMO is incompatible with life, while hypomorphic mutations result in an X-linked recessive disorder with immunodeficiency, anhidrosis, abnormal teeth, and ectodermal dysplasia $(14,15)$. The ectodermal defects in NEMO are due to the inability of the ectodysplasin A receptor to induce $\mathrm{NF}-\kappa \mathrm{B}$ activation. Patients with NEMO defects are susceptible to all pathogens, including invasive pyogenic infections with S. pneumoniae, Haemophilus influenzae, S. aureus, mycobacteria, fungi, and viruses. This disease is highly variable in its clinical presentation depending on the nature of the specific mutation. Patients have also been described to have osteopetrosis, vascular anomalies, autoimmunity, colitis, and arthritis. Routine labs in these patients can be normal; however, defective natural killer function and TLR signaling are the most consistent findings (16). Treatment includes antibiotic prophylaxis to prevent mycobacteria and Pneumocystis, and if patients have impaired B cell immunity, immunoglobulin therapy should also be administered. If there is functional B cell immunity, patients 
should be up to date on their vaccinations to $S$. pneumoniae, $H$. influenzae, and Neisseria meningitidis (12).

I $\mathrm{B} \alpha$ deficiency has a similar phenotype to NEMO, with ectodermal dysplasia and variable immunodeficiency, but exhibits autosomal dominant inheritance (17). Point mutations that affect the serine phosphorylation sites result in the most severe phenotype, with hypogammaglobulinemia, poor specific antibody production, and low proportions of CD4 and CD8 T cells. They are prone to recurrent bacterial infections including $S$. aureus, S. pneumoniae, P. aeruginosa, and Salmonella enterica and opportunistic infections like Candidiasis and Pneumocystis jiroveci. Autoimmunity can be seen in these patients as well, predominately manifested as recurrent diarrhea or colitis. Treatment also includes immunoglobulin therapy for impaired B cell immunity and antibiotic prophylaxis to S. pneumoniae, $H$. influenza, and $N$. meningitidis (12). Hematopoietic stem cell transplant has been completed with improvement of the primary immunodeficiency, but patients will persist with their ectodermal dysplasia (18). A milder form of this disease can be seen with certain nonsense mutations (19).

I $\kappa \mathrm{B}$ kinase $\beta$, one of the kinases of the IKK complex responsible for phosphorylation of $\mathrm{I} \kappa \mathrm{B} \alpha$ or $\mathrm{I} \kappa \mathrm{B} \beta$, results in an autosomal recessive immunodeficiency. Clinical presentation resembles both I $\mathrm{B} \alpha$ and NEMO mutations (3). Affected patients present in infancy with life-threatening bacterial, fungal, and viral infections and failure to thrive. Laboratory studies showed hypogammaglobulinemia with relatively normal numbers of circulating $\mathrm{B}$ and $\mathrm{T}$ cells, although the $\mathrm{T}$ cells in these patients are largely naive. $\mathrm{T}$ and $\mathrm{B}$ cell mitogen responses can be affected $(20,21)$.

The NF- $\mathrm{\kappa B}$ complex is made up of homo- or heterodimers of several transcription factors: cRel, RelA/p65, RelB, p50, and $\mathrm{p} 52$. The $\mathrm{p} 50$ and $\mathrm{p} 52$ proteins are generated from longer precursors, p105 and p100, respectively. The p105 protein is encoded by NFKB1, whereas the p100 protein is encoded by NFKB2. Genetic defects in NFKB1 or NFKB2 result in common variable immunodeficiency with hypogammaglobulinemia, recurrent infections, and autoimmunity. Both of these disorders are inherited in an autosomal dominant manner, but exhibit variable penetrance and varying ages of presentation. NFKB2 deficiency also results in central adrenal insufficiency and other pituitary defects (22-25).

In four patients of Cree ancestry from Canada with primary immunodeficiency-15 (IMD15; 615592), Pannicke et al. (20) identified a homozygous truncating mutation in the IKBKB gene (c.1292dupG; 603258.0001), resulting in complete loss of protein function. The mutation was found by homozygosity mapping followed by sequencing of genes in the candidate region. The patients presented in infancy with life-threatening bacterial, fungal, and viral infections and failure to thrive. Laboratory studies showed hypo- or agammaglobulinemia with relatively normal numbers of circulating $\mathrm{B}$ and $\mathrm{T}$ cells. Functional and gene expression studies of patient fibroblasts showed variable effects on receptor activation and NFKB signaling involved in immunity. There was impaired phosphorylation of NFKBIA (164008) in response to stimulation with TNFA (191160) and flagellin, which acts through TLR5 (603031), but only a marginally impaired response to IL1B (147720). IL6 (147620) response to TNFA was normal, but it was reduced in response to lipopolysaccharide, with acts through TLR4 (603030). These studies showed selective dependence of the regulation of NFKB target genes on IKBKB function. Patient peripheral blood $B$ and $\mathrm{T}$ cells were almost exclusively of the naive type, and $\mathrm{B}, \mathrm{T}$, and NK cells showed poor differentiation or mitogenic responses under certain conditions. These findings were consistent with the role of IKBKB in transmitting signals by various surface receptors.

In a Turkish infant, born of consanguineous parents, with fatal IMD15, Nielsen et al. (21) identified a homozygous truncating mutation in the IKBKB gene (R272X; 603258.0002). The mutation was found by whole-exome sequencing. Western blot analysis of patient cells showed a complete lack of the IKBKB protein, although IKKA (CHUK; 600664) and NEMO (IKBKG; 300248) levels were similar to control. Stimulation of patient T cells failed to result in phosphorylation of p65 (NFKB3; 164014), and patient $\mathrm{T}$ cells failed to proliferate in response to stimulation. The findings indicated that IKBKB is critical for activation of $\mathrm{T}$ cells and differentiation of $\mathrm{B}$ cells.

\section{TLR3 Pathway Defects}

Inborn errors of the TLR3 pathway can also result in immunodeficiency. TLR3-deficient patients suffer from recurrent herpes simplex encephalitis (26). TLR3 recognizes viral nucleic acids intracellularly, resulting in interferon production to limit virus spread (27). Mutations in TRAF3, TRIF, and UNC93B1 defects, proteins involved in signaling of TLR3, also result in recurrent herpes simplex encephalitis UNC93B1 is an intracellular endoplasmic reticulum protein involved in translocation of TLR3, TLR7, TLR8, and TLR9 into the endosome to meet with their ligands. This disorder is autosomal recessive and resulting in markedly lower levels of IFN $\alpha$, IFN $\beta$, and IFN $\gamma$ in response to virus (28). Tumor necrosis factor TRAF3 is also involved in signaling through TLR3, and dominant-negative mutations in TLR3 result in impairment of binding to dsRNA and defective production of IFN $\alpha, \operatorname{IFN} \beta$, and IFN $\gamma$ (29). The low levels of IFN $\alpha$, IFN $\beta$, and IFN $\gamma$ with viral stimulation result in high levels of viral replication and eventual cell death (26). TRIF specifically interacts with TLR3 and is required for signal transduction of this pathway. TRIF is also involved in TLR4 signaling. TRIF deficiency is autosomal recessive or autosomal dominant, presents with herpes encephalitis, and fibroblast from these patients demonstrated defective interferon and IL- 6 production in response to TLR3 agonists (30). Function of TLR3, UNC93B1, TRIF, and TRAF3 appears to be crucial in neurons to control virus, but is expendable in other tissues. Diagnostic testing can be difficult as neuronal cells or fibroblasts will show a defect when tested, but peripheral blood mononuclear cell responses can be normal. Treatment with interferon along with acyclovir may improve prognosis (29).

Our patient had recurrent $S$. pneumoniae infections despite a largely normal immune workup, and without significant signs of infections, such as fever, even during episodes of bacteremia. This case highlights the importance of evaluating 
TLR signaling in any infant with recurrent or severe pyogenic infections. Recognition of these disorders is crucial as these patients present early in infancy often with blunted inflammatory responses that can lead to delayed diagnosis and grave outcomes.

\section{ETHICS STATEMENT}

This study was carried out in accordance with the recommendations of the Children's Hospital of Wisconsin Institutional Review

\section{REFERENCES}

1. Murphy K. Janeway's Immunology. 8th ed. Garland Science (2011).

2. Kawai T, Akira S. Toll-like receptors and their crosstalk with other innate receptors in infection and immunity. Immunity (2011) 34(5):637-50. doi:10.1016/j.immuni.2011.05.006

3. Burns SO, Plagnol V, Gutierrez BM, Zahrani DA, Curtis J, Gaspar M, et al. Immunodeficiency and disseminated mycobacterial infection associated with homozygous nonsense mutation of IKK $\beta$. J Allergy ClinImmunol (2014) 134(1):215-8.e3. doi:10.1016/j.jaci.2013.12.1093

4. Gilmore TD. Introduction to NF-kappaB: players, pathways, perspectives. Oncogene (2006) 25(51):6680-4. doi:10.1038/sj.onc.1209954

5. Ku CL, Picard C, Erdös M, Jeurissen A, Bustamante J, Puel A, et al. IRAK4 and NEMO mutations in otherwise healthy children with recurrent invasive pneumococcal disease. JMed Genet (2007) 44(1):16-23. doi:10.1136/ jmg.2006.044446

6. Ku CL, von Bernuth H, Picard C, Zhang SY, Chang HH, Yang K, et al. Selective predisposition to bacterial infections in IRAK-4-deficient children: IRAK4-dependent TLRs are otherwise redundant in protective immunity. J Exp Med (2007) 204(10):2407-22. doi:10.1084/jem.20070628

7. von Bernuth H, Picard C, Jin Z, Pankla R, Xiao H, Ku CL, et al. Pyogenic bacterial infections in humans with MyD88 deficiency. Science (2008) 321(5889):691-6. doi:10.1126/science.1158298

8. Conway DH, Dara J, Bagashev A, Sullivan KE. Myeloid differentiation primary response gene 88 (MyD88) deficiency in a large kindred. J Allergy ClinImmunol (2010) 126(1):172-5. doi:10.1016/j.jaci.2010.04.014

9. Suhir H, Etzioni A. The role of toll-like receptor signaling in human immunodeficiencies. Clin Rev Allergy Immunol (2010) 38(1):11-9. doi:10.1007/ s12016-009-8135-0

10. Picard C, von Bernuth H, Ghandil P, Chrabieh M, Levy O, Arkwright PD, et al. Clinical features and outcome of patients with IRAK-4 and MyD88 deficiency. Medicine (2010) 89(6):403-25. doi:10.1097/MD.0b013e3181fd8ec3

11. Frans G, Moens L, Schrijvers R, Wuyts G, Bouckaert B, Schaballie H, et al. PID in disguise: molecular diagnosis of IRAK-4 deficiency in an adult previously misdiagnosed with autosomal dominant hyper IgE syndrome. J Clin Immunol (2015) 35(8):739-44. doi:10.1007/s10875-015-0205-x

12. Picard C, Casanova J-L, Puel A. Infectious diseases in patients with IRAK-4, MyD88, NEMO, or IкB $\alpha$ deficiency. Clin Microbiol Rev (2011) 24(3):490-7. doi:10.1128/CMR.00001-11

13. Puel A, Picard C, Ku CL, Smahi A, Casanova JL. Inherited disorders of NF-kappaB-mediated immunity in man. Curr Opin Immunol (2004) 16(1):34-41. doi:10.1016/j.coi.2003.11.013

14. Zonana J, Elder ME, Schneider LC, Orlow SJ, Moss C, Golabi M, et al. A novel X-linked disorder of immune deficiency and hypohidrotic ectodermal dysplasia is allelic to incontinentia pigmenti and due to mutations in IKKgamma (NEMO). Am J Hum Genet (2000) 67(6):1555-62. doi:10.1086/316914

15. Döffinger R, Smahi A, Bessia C, Geissmann F, Feinberg J, Durandy A, et al. X-linked anhidrotic ectodermal dysplasia with immunodeficiency is caused by impaired NF-kappaB signaling. Nat Genet (2001) 27(3):277-85. doi: $10.1038 / 85837$

16. Hanson EP, Monaco-Shawver L, Solt LA, Madge LA, Banerjee PP, May MJ, et al. Hypomorphic nuclear factor- $\kappa \mathrm{B}$ essential modulator mutation database and reconstitution system identifies phenotypic and immunologic
Board with written informed consent from all subjects. As a single case report, this work was exempt from IRB review.

\section{AUTHOR CONTRIBUTIONS}

KG was the primary author and gathered all of the information and wrote the manuscript. MH was involved in obtaining and analyzing clinical data. JR and JV aided with manuscript preparation and review. $\mathrm{BB}, \mathrm{MC}, \mathrm{PG}, \mathrm{AP}, \mathrm{CP}$, and J-LC did all of the genetic testing and functional testing reported in the manuscript.

diversity. J Allergy ClinImmunol (2008) 122(6):1169-77.e16. doi:10.1016/ j.jaci.2008.08.018

17. Courtois G, Smahi A, Reichenbach J, Döffinger R, Cancrini C, Bonnet M, et al. A hypermorphic I $\mathrm{B} \alpha$ mutation is associated with autosomal dominant anhidrotic ectodermal dysplasia and $\mathrm{T}$ cell immunodeficiency. J Clin Invest (2003) 112(7):1108-15. doi:10.1172/JCI18714

18. Dupuis-Girod S, Cancrini C, Le Deist F, Palma P, Bodemer C, Puel A, et al. Successful allogeneic hemopoietic stem cell transplantation in a child who had anhidrotic ectodermal dysplasia with immunodeficiency. Pediatrics (2006) 118(1):e205-11. doi:10.1542/peds.2005-2661

19. Lopez-Granados E, Keenan JE, Kinney MC, Leo H, Jain N, Ma CA, et al. A novel mutation in NFKBIA/IKBA results in a degradation-resistant $\mathrm{N}$-truncated protein and is associated with ectodermal dysplasia with immunodeficiency. Hum Mutat (2008) 29(6):861-8. doi:10.1002/ humu. 20740

20. Pannicke U, Baumann B, Fuchs S, Henneke P, Rensing-Ehl A, Rizzi M, et al. Deficiency of innate and acquired immunity caused by an IKBKB mutation. N Engl J Med (2013) 369(26):2504-14. doi:10.1056/NEJMoa1309199

21. Nielsen C, Jakobsen MA, Larsen MJ, Müller AC, Hansen S, Lillevang ST, et al. Immunodeficiency associated with a nonsense mutation of IKBKB. J Clin Immunol (2014) 34(8):916-21. doi:10.1007/s10875-014-0097-1

22. Chen K, Coonrod EM, Kumánovics A, Franks ZF, Durtschi JD, Margraf RL, et al. Germline mutations in NFKB2 implicate the noncanonical NF-kappaB pathway in the pathogenesis of common variable immunodeficiency. Am J Hum Genet (2013) 93(5):812-24. doi:10.1016/j.ajhg.2013.09.009

23. Lee CE, Fulcher DA, Whittle B, Chand R, Fewings N, Field M, et al. Autosomaldominant B-cell deficiency with alopecia due to a mutation in NFKB2 that results in nonprocessable p100. Blood (2014) 124(19):2964-72. doi:10.1182/ blood-2014-06-578542

24. Brue T, Quentien MH, Khetchoumian K, Bensa M, Capo-Chichi JM, Delemer B, et al. Mutations in NFKB2 and potential genetic heterogeneity in patients with DAVID syndrome, having variable endocrine and immune deficiencies. BMC Med Genet (2014) 15:139. doi:10.1186/ s12881-014-0139-9

25. Fliegauf M, Bryant VL, Frede N, Slade C, Woon ST, Lehnert K, et al. Haploinsufficiency of the NF-kappaB1 subunit p50 in common variable immunodeficiency. Am J Hum Genet (2015) 97(3):389-403. doi:10.1016/ j.ajhg.2015.07.008

26. Zhang SY, Jouanguy E, Ugolini S, Smahi A, Elain G, Romero P, et al. TLR3 deficiency in patients with herpes simplex encephalitis. Science (2007) 317(5844):1522-7. doi:10.1126/science.1139522

27. Hanke ML, Kielian T. Toll-like receptors in health and disease in the brain: mechanisms and therapeutic potential. Clin Sci (Lond) (2011) 121(9):367-87. doi:10.1042/CS20110164

28. Casrouge A, Zhang SY, Eidenschenk C, Jouanguy E, Puel A, Yang K, et al. Herpes simplex virus encephalitis in human UNC-93B deficiency. Science (2006) 314(5797):308-12. doi:10.1126/science.1128346

29. Pérez de Diego R, Sancho-Shimizu V, Lorenzo L, Puel A, Plancoulaine S, Picard C, et al. Human TRAF3 adaptor molecule deficiency leads to impaired toll-like receptor 3 response and susceptibility to herpes simplex encephalitis. Immunity (2010) 33(3):400-11. doi:10.1016/j.immuni.2010.08.014

30. Sancho-Shimizu V, Pérez de Diego R, Lorenzo L, Halwani R, Alangari A, Israelsson E, et al. Herpes simplex encephalitis in children with 
autosomal recessive and dominant TRIF deficiency. J Clin Invest (2011) 121(12): 4889-902. doi:10.1172/JCI59259

Conflict of Interest Statement: The authors declare that the research was conducted in the absence of any commercial or financial relationships that could be construed as a potential conflict of interest.
Copyright (๑) 2017 Gobin, Hintermeyer, Boisson, Chrabieh, Ghandil, Puel, Picard, Casanova, Routes and Verbsky. This is an open-access article distributed under the terms of the Creative Commons Attribution License (CC BY). The use, distribution or reproduction in other forums is permitted, provided the original author(s) or licensor are credited and that the original publication in this journal is cited, in accordance with accepted academic practice. No use, distribution or reproduction is permitted which does not comply with these terms. 